DOI: $10.1515 / \mathrm{adms}-2015-0019$

\author{
A. Kausar \\ Nanosciences and Catalysis Division, National Centre For Physics, Quaid-i-Azam University \\ Campus, 44000, Islamabad, Pakistan \\ asheesgreat@yahoo.com
}

\title{
EFFECT OF NANOFILLER DISPERSION ON MORPHOLOGY, MECHANICAL AND CONDUCTING PROPERTIES OF ELECTROACTIVE SHAPE MEMORY POLY(URETHANE-UREA)/FUNCTIONAL NANODIAMOND COMPOSITE
}

\begin{abstract}
In this attempt, segmented poly(urethane urea) was prepared from polycaprolactone triol (soft segment), 1,3bis(isocyanatomethyl)cyclohexane (hard segment) and 4,5-diaminophthalonitrile (chain extender). Acidfunctionalized nano-diamond was used as nano-filler. The nanocomposites were processed using solution casting and melt blending. Unique morphology was observed by SEM due to generation of crosslinked polyurethane and ND network. The s-PUU/ND 10 depicted $6 \%$ increase in tensile strength compared with m-PUU/ND $10.10 \mathrm{wt} . \% \mathrm{ND}$ loading via solution route increased conductivity to $0.089 \mathrm{Scm}^{-1}$ relative to m-PUU/ND $10\left(0.057 \mathrm{Scm}^{-1}\right)$. Electrical conductivity of nanocomposites was enough to show electroactive shape recovery of $95 \%(40 \mathrm{~V})$.
\end{abstract}

Keywords: Poly(urethane urea); nanodiamond; electroactive shape recovery

\section{INTRODUCTION}

Shape memory polymers (SMPs) have numerous advantages over shape memory alloys to be utilized in technical requisitions. The important features are the superior restorable strain (well above 100\%), low cost, and low density [1]. Even though chemo-responsive and photoresponsive SMPs have been produced, presently the most well-known SMPs are thermoresponsive SMPs. Shape memory alloys can be activated directly by Joule heating effect i.e. by the direct passage of an electrical current for the purpose of heating $[2,3]$. However it is complicated to heat the polymers due to their intrinsically non-conductive nature. The electrically conductive SMPs can be recognized by their blending with different types of conductive additives such as carbon black $[4,5]$. The actuation still cannot be initiated in a wireless way in SMPs. Recent developments in thermo-responsive SMP activating technologies include heating of SMP composites [6, 7]. Another development in thermo-responsive SMP activating technologies is laser heating. However laser heating is only appropriate for some particular transparent SMPs [8]. 
Polymers with shape-memory features usually consist of two molecular segments or components. Firstly the net points or cross-links describe the permanent shape either through chemical bonds or physical interaction. Secondly the switching segments allow the impermanent shape fitting by establishing a switch able second network. For instance the semi crystalline or glass phase is formed that can be unstiffened upon heating to a corresponding transition temperature [9, 10]. The elasticity of cross links formed due to chemical bonds or physical interaction affects the properties of shape-memory polymers. For that reason the shape memory effect directly depends on the micro-phase partition of blocks or segments. The phase separation in turn determines the molecular physiognomies such as molecular composition and weight of two blocks [11]. Polyurethane (PU) have been reported as moisture sensitive as well as thermal-responsive SMP [12]. It is well known that polyurethane-urea is a segmented type copolymer. The unusual features of such material resources have been accredited to the creation of micro-phase separated domain assembly comprising of "soft"-segment-rich and "hard"-segment-rich domains. The softsegment based domains are elastic at service temperature while the hard-segment domains are glassy. The glassy domains act as thermally reactive cross linking points. This kind of thermal stability renders polyurethanes as thermoplastic materials. The structure-property relationship of polyurethane-urea has been focused due to their technical applications. Polyurethane-urea is utilized in almost all industrial sectors [13, 14]. The recovery of moisture-responsive and thermal-responsive SMP materials is well-regulated in programmable mode and/or in water [15]. However the main problematic feature of SMPs is their low retrieval which restricts the SMP's capability to recover when confronted with huge mechanical resilience. To overcome this problem SMP nanocomposites have been produced with improved mechanical properties [16]. In this regard various types of nanofillers (metal nano-powder, nano-ceramic, carbon nanotube, nano-silica and nano-clay) have been employed to strengthen the polymer matrix [17]. The thermal-mechanical performance of the PU/clay nanocomposites have been investigated [18-20]. The researches have previously reported the electro-triggered polymeric composites. The electrical conductivity of shape-memory polyurethane composites having low carbon black loading was found to be high [21]. The shape-memory polyurethane-based composites integrated with 5 wt.\% surface-altered multi-walled carbon nanotube had the electrical conductivity of $10^{-3}$ $\mathrm{S} \mathrm{cm}^{-1}[22]$. Similarly nanodiamaond (ND) can be active candidates in this regard. However ND is relatively less explored nanofiller in SMPs. In this paper we have focused on the preparation of conductive and flexible composites of novel segmented poly(urethane urea) (PUU) and nanodiamond. In this attempt SMPs have been processed using solution as well as melt techniques. The voltage-triggered shape memory effect was studied. Affect of the applied processing technique and PUU structure on the conductivity and shape memory properties was investigated. These materials can be potentially useful in industrial applications where high conductivity and shape memory properties are important consideration.

\section{EXPERIMENTAL}

\section{Materials}

Diamond nanopowder (nanopowder, $<10 \mathrm{~nm}$ particle size (TEM), $\geq 97 \%$ trace metals basis) were obtained from Aldrich (St. Louis, USA). X-Ray diffraction conforms to the structure of the nanodiamond produced from detonation method. Trace metal analysis was $<30000.0 \mathrm{ppm}$. All 
other chemicals employed in present work such as 1,3-bis(isocyanatomethyl)cyclohexane (colorless liquid, 99\%), polycaprolactone triol (softening point $30{ }^{\circ} \mathrm{C}$, density $\sim 1.08 \mathrm{~g} / \mathrm{mL}$ at 25 ${ }^{\circ} \mathrm{C}$, average $\mathrm{M}_{\mathrm{n}} \sim 900$ ), 4,5-diaminophthalonitrile (mp 270-276 ${ }^{\circ} \mathrm{C} \quad 95 \%$ ) and $\mathrm{N}, \mathrm{N}-$ dimethylformamide (DMF, $\geq 99.8 \%$, grade anhydrous) were supplied by Aldrich (St. Louis, USA). The chemicals were of high purity and were used as received.

\section{Characterization techniques}

IR spectra were taken at room temperature with a resolution of $4 \mathrm{~cm}^{-1}$ using Excalibur Series BIO-RAD FTIR Spectrometer, Model No. FTSW 300 MX (California, USA). The scanning electron microscopic (SEM) images were obtained by Scanning Electron Microscope Model No. S-4700 (Japan Hitachi Co. Ltd.). Waters Alliance Model No. GPCV2000 (California, USA) was used to determine the weight-average molecular weight $\left(\mathrm{M}_{\mathrm{w}}\right)$ and polydispersity index (PDI). Stress-strain behavior was examined using a universal testing machine Model No. Instron 4466 (NJ, USA) with a strain rate of $5 \mathrm{~mm} / \mathrm{min}$ at $25^{\circ} \mathrm{C}$ according to ASTM D638 standard method. Sample dimension were equal to $40 \times 10 \times 1 \pm 0.01 \mathrm{~mm}^{3}$. The electrical conductivity was measured at room temperature using four-point Model No. Keithley 2401 (Duisburg, Germany). The thermal conductivity of samples was measured using a HotDisk Transient Plane Source Model No.TPS $2500 \mathrm{~S}$ (HotDisk AB). The system uses a nickel wire wound in two intertwined spirals as a sensor. An electrical pulse with a power $0.03-0.5 \mathrm{~W}$ in the nickel generates a heat pulse that raises the temperature of the sample. All measurements were performed at $25^{\circ} \mathrm{C}$. The rectangular samples with dimensions $40 \times 10 \times 1 \pm 0.01 \mathrm{~mm}^{3}$ were used for conductivity measurement. The shape-memory effect of rectangular strips with dimension $40 \times 10 \times 1 \pm 0.01 \mathrm{~mm}^{3}$ was observed at 25 and $40 \mathrm{~V}$. The shape recovery was calculated using the equation (1):

$$
\text { Shape recovery }(\%)=[(90-\theta) / 90] \times 100
$$

\section{Synthesis of poly(urethane-urea) (PUU)}

Shape memory PUU was synthesized from its monomers using two-step process. The desired amount of 1,3-bis(isocyanatomethyl)cyclohexane was dehydrated at $60{ }^{\circ} \mathrm{C}$ for $24 \mathrm{~h}$. The polycaprolactone triol was also dehydrated at $60{ }^{\circ} \mathrm{C}$ for $24 \mathrm{~h}$. The polyol and diisocyanate were sonicated in $20 \mathrm{~mL}$ DMF $(\mathrm{NCO} / \mathrm{OH}=1.1: 1)$ with steady stirring of $10 \mathrm{~h}$. The 4,5diaminophthalonitrile (equimolar) was dissolved separately in $10 \mathrm{~mL}$ of DMF with constant stirring of $6 \mathrm{~h}$. The above mixtures were then mixed and refluxed at $80^{\circ} \mathrm{C}$ for $12 \mathrm{~h}$ [23]. Later the mixture was cast in Teflon mold and cured at $80{ }^{\circ} \mathrm{C}$ to obtain PUU film (Fig. 1). $\mathrm{M}_{\mathrm{w}}=20 \times 10^{3}$ gmol $^{-1} ; \mathrm{PDI}=2 ; \%$ Yield $=90 \%$.

\section{Functionalization of nanodiamond (ND)}

Prior to use, ND was annealed at $300{ }^{\circ} \mathrm{C}$ to remove any impurities present. To introduce carboxylic acid groups on the surface of nanodiamond, a mixture of strong acids was used [24]. Consequently, ND was treated with the mixture of strong acids $\left(\mathrm{H}_{2} \mathrm{SO}_{4}\right.$ and $\mathrm{HNO}_{3}$ in the ratio of $3: 1$, respectively) at $30{ }^{\circ} \mathrm{C}$ for $24 \mathrm{~h}$. The resultant mixture was poured into $200 \mathrm{~mL}$ hot water $(70$ 
${ }^{\circ} \mathrm{C}$ ) and stirred for $10 \mathrm{~h}$. The product obtained was filtered and washed repeatedly with deionized water and dried at $80{ }^{\circ} \mathrm{C}$ [24]. FTIR $\left(\mathrm{KBr}, \mathrm{cm}^{-1}\right)$ : 3479 (hydroxyl $\mathrm{O}-\mathrm{H}$ stretch), 3003 (aromatic $\mathrm{C}-\mathrm{H}$ stretch), 1720 (carboxylic acid $\mathrm{C}=\mathrm{O}$ stretch), $1190\left(\mathrm{~S}=\mathrm{O}\right.$ stretch), 1040 (symmetric $\mathrm{SO}_{3} \mathrm{H}$ stretch).
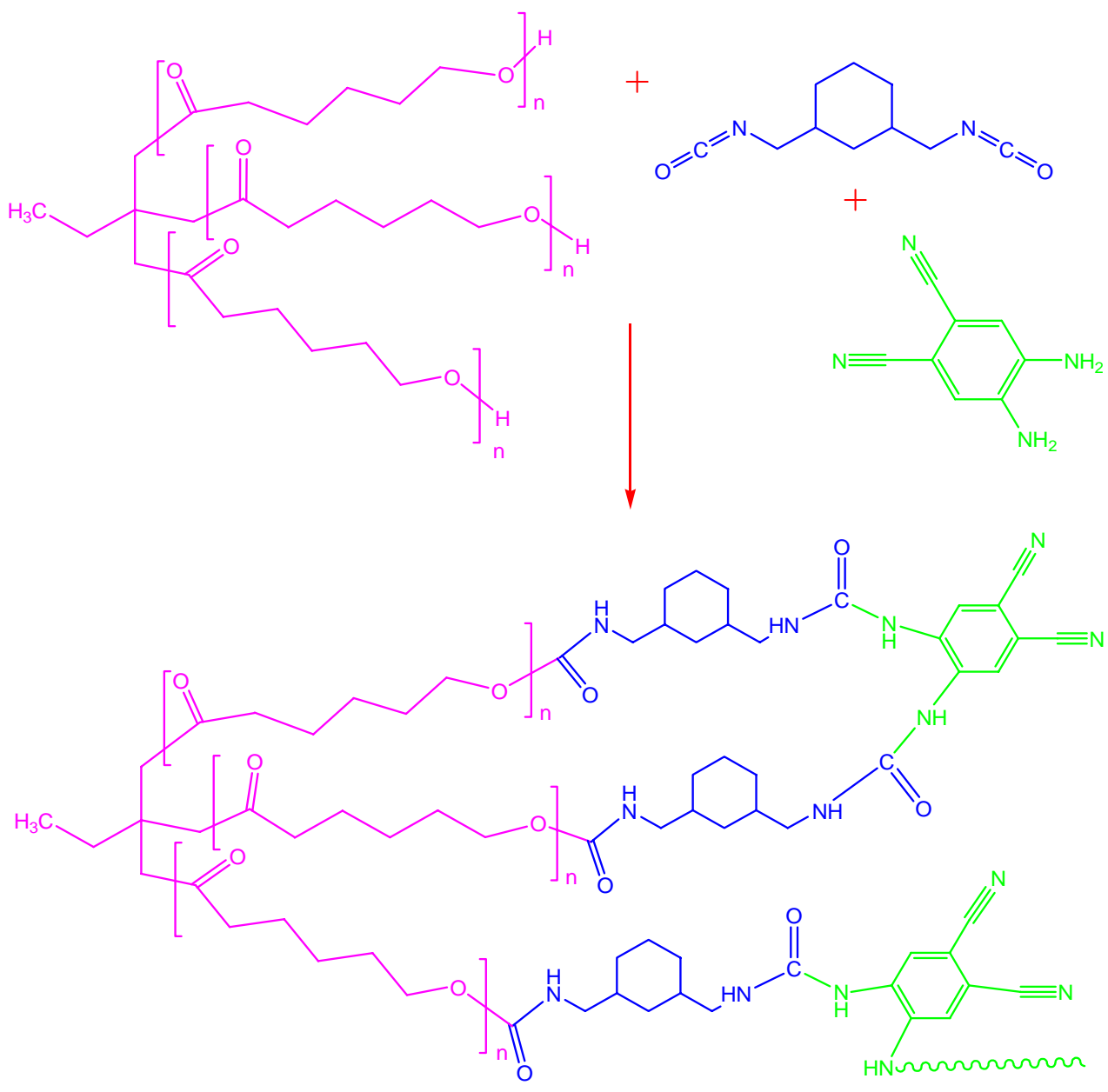

Fig. 1. Schematic preparation of poly(urethane-urea)

\section{Preparation of s-PUU/ND nanocomposite via solution route}

s-PUU/ND composite was prepared using the similar procedure mentioned in Section 2.3. However after refluxing with diamine the desired ND content (1, 3, 5, 10 wt. \%) was added and the mixture was refluxed for $24 \mathrm{~h}$ before film casting (Fig. 2).

\section{Preparation of $\mathrm{m}-\mathrm{PUU} / \mathrm{ND}$ nanocomposite via melt route}

PUU was prepared using the similar procedure mentioned in Section 2.3. The preferred amount of PUU was melt blended with the desired ND content $(1,3,5,10$ wt. \%). The m-PUU/ND composite was prepared using a Brabender Plasticorder mixer at $200{ }^{\circ} \mathrm{C}$ [25]. 


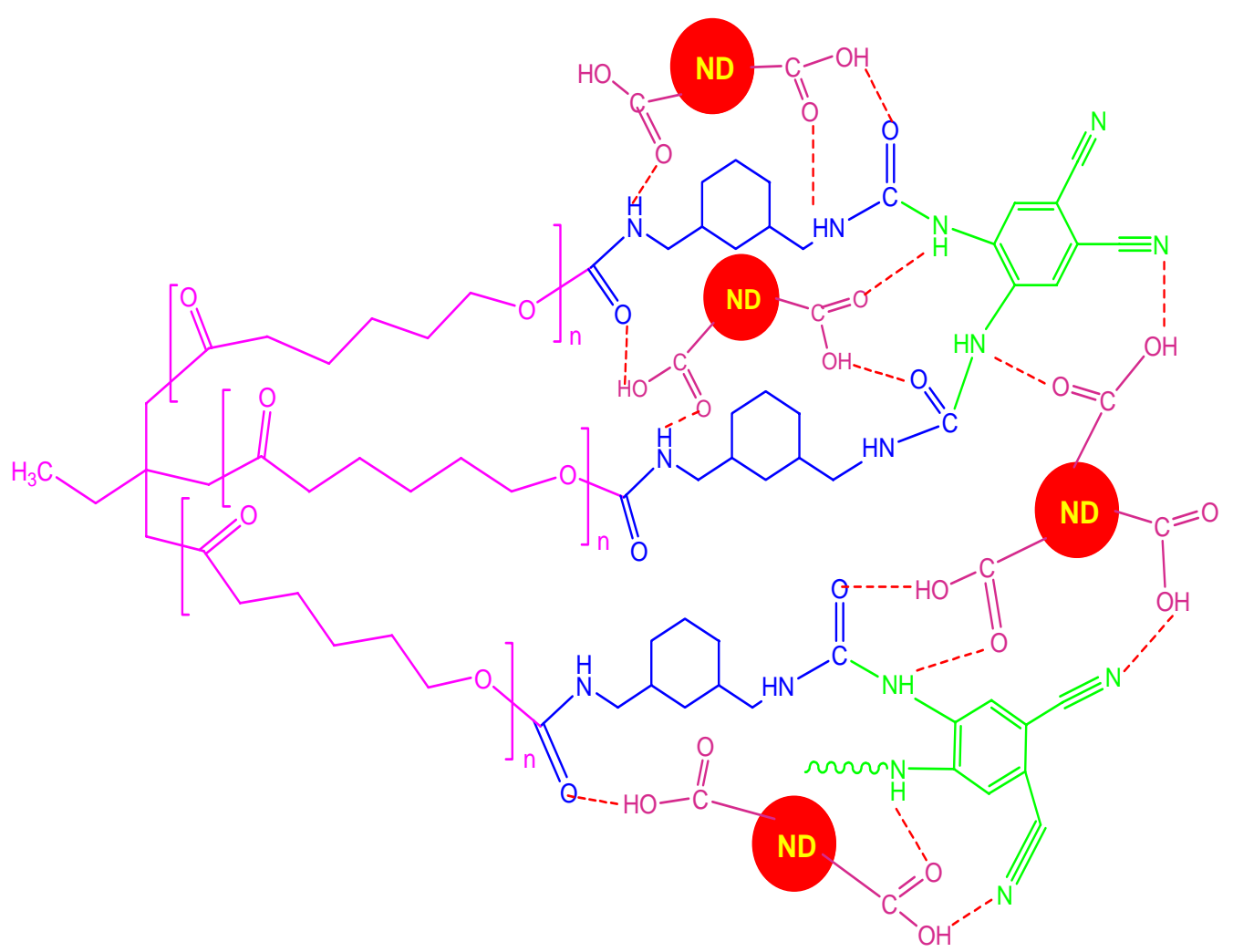

Fig. 2. Representation of PUU/ND nanocomposite

\section{RESULTS AND DISCUSSION}

\section{FTIR analysis}

FT-IR spectrum of PUU is given in Fig. 3A. Carbonyl peaks for urea and urethane structure appear at 1720 and $1745 \mathrm{~cm}^{-1}$. Amide $\mathrm{N}-\mathrm{H}$ stretching and bending vibrations also appear at 3221 and $1591 \mathrm{~cm}^{-1}$ respectively. The aliphatic and aromatic protons are observed near 2928 and $3009 \mathrm{~cm}^{-1}$. The $\mathrm{C}-\mathrm{O}$ stretching vibration is found at $1270 \mathrm{~cm}^{-1}$ and $\mathrm{C}-\mathrm{N}$ stretch appear at $1435 \mathrm{~cm}^{-1}$. The hydroxyl group stretching vibration at $3401 \mathrm{~cm}^{-1}$ was related to the un-reacted $\mathrm{O}-\mathrm{H}$ polyol functionality. The PUU/ND1 (Fig. 3B) displayed almost all characteristic bands of polyurethane urea found in the resulting spectrum. However, there is shift in the $\mathrm{N}-\mathrm{H}$ stretching and bending vibrations to lower wave number due to the presence of interaction between the PUU and acid functionalized ND. The carbonyl peaks are also shifted to lower wave numbers due to the presence of secondary interaction. Therefore, carbonyl functionalities appear at 1716 and $1729 \mathrm{~cm}^{-1}$. The $\mathrm{N}-\mathrm{H}$ stretching and bending vibration is also found at lower wave number (3201 and $1590 \mathrm{~cm}^{-1}$ respectively). Similar to PUU spectrum, the aliphatic and aromatic protons are found at 2911 and 3001 $\mathrm{cm}^{-1}$. The composite display peaks related to $\mathrm{C}-\mathrm{O}$ at $1269 \mathrm{~cm}^{-1}$ and $\mathrm{C}-\mathrm{N}$ stretch at $1430 \mathrm{~cm}^{-}$ 1 . 


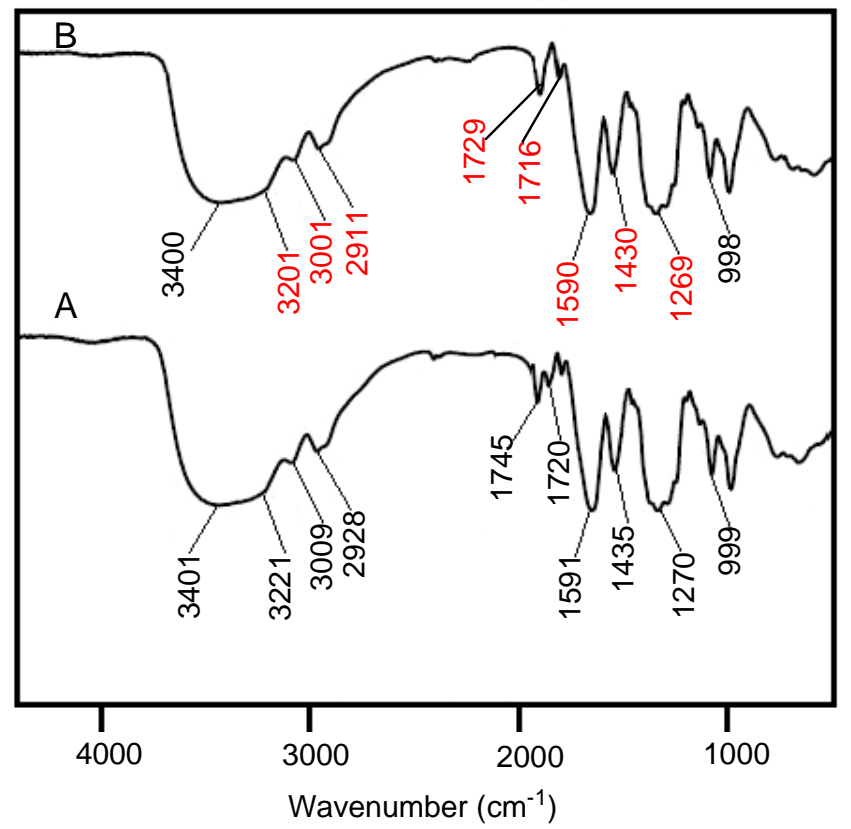

Fig. 3. FTIR of (A) poly(urethane-urea); (B) s-PUU/ND 1 composite

\section{Morphology investigation}

Fig. 4 shows the FESEM images of m-PUU/ND 1, m-PUU/ND 5 and $m-P U U / N D 10$ composites. The micrograph of m-PUU/ND 1 composite (Fig. 4A) depict complete aggregation of polymer matrix and the morphology was found irregular. The m-PUU/ND 5 composite in Fig. 4B shows less aggregated structure however non-uniform dispersion of nanofiller was observed in the matrix. Similarly, Fig. 4C with 10 wt. \% nanodiamond reveals non-consistent dispersion of the filler in matrix. The results showed that the melt blending was not a successful technique to form well-dispersed poly(urethane urea)/nanodiamond composites. Consequently the tensile and shape memory properties were affected by the poor matrix/filler dispersion. On the other hand the morphology of solution processed composites was entirely different. All the micrographs in Fig. 5 (s-PUU/ND 1, s-PUU/ND 5 and s-PUU/ND 10) depict well-aligned pattern without any polymer or nanofiller aggregation. Some brushwood or network of PUU and nanodiamomd was also visible in Fig. 5 B \& C. The exclusive morphology suggested that the nnaodiamond phase was incorporated into the poly(urethane urea) [26]. The network was observed due to the generation of cross linked polymer/ND network [27]. This phenomenon is often exhibited by shape memory polyurethanes having cross linked structure. Here the poly(urethane-urea) was branched due to the polycaprolactone triol segment used and cross linked due to acidfunctionalized nanodiamond. The micrographs reveal better filler dispersion and hence the success of the solution technique used. 


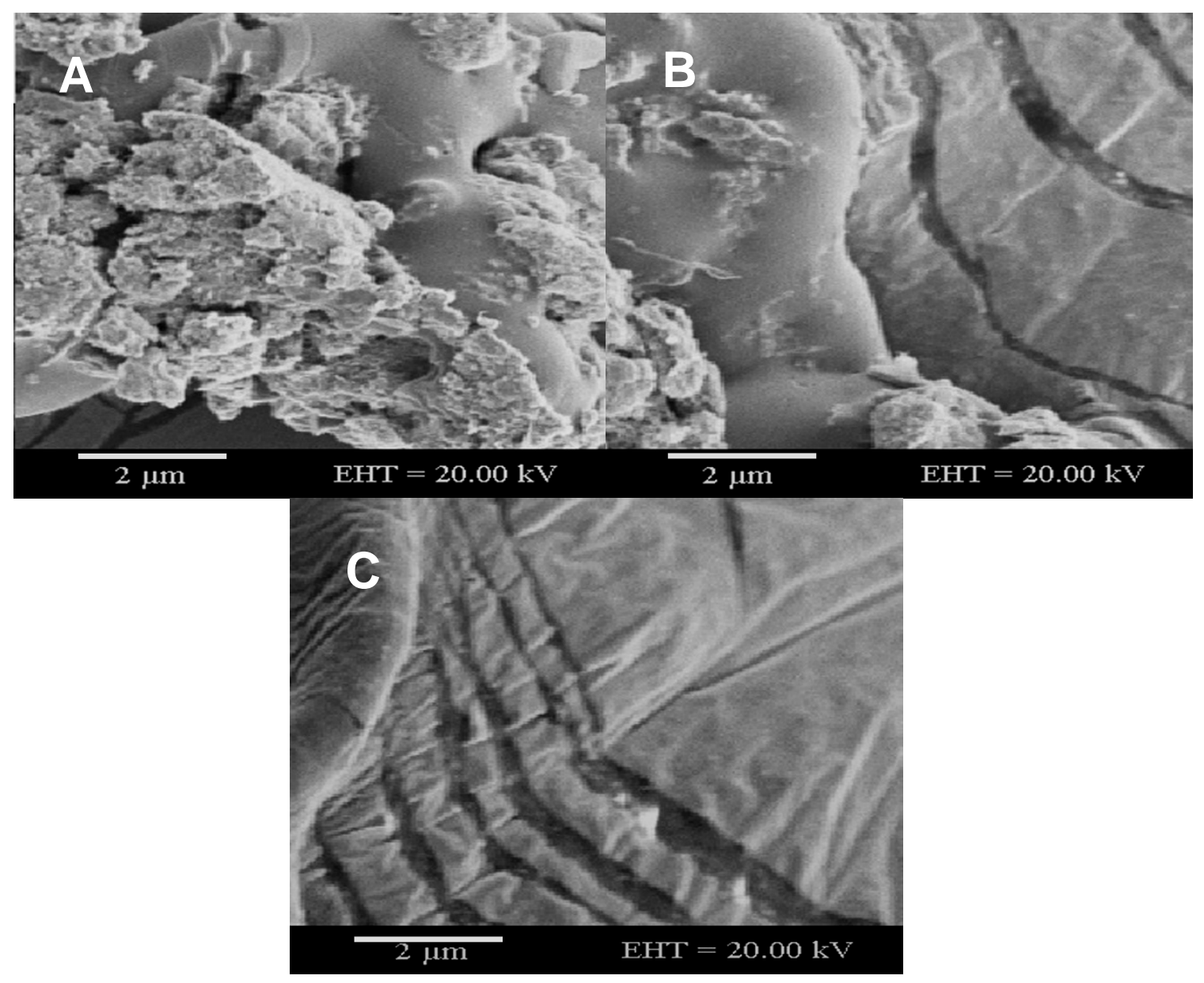

Fig. 4. FESEM images of (A) m-PUU/ND 1; (B) m-PUU/ND 5; and (C) m-PUU/ND 10.

During the PUU synthesis in DMF solvent, the nanodiamond was added and refluxed for longer time period to form homogeneous dispersion of filler. In solution route ND was not separately dispersed in DMF prior to addition in PUU, because solvent was already present in polymer to disperse the particles. However in the melt route absence of solvent greatly affect the ND dispersion and hence the final composite morphology. Another important reason for better dispersion of nanodiamond in PUU matrix was the chemical interaction between PUU and nanodiamond. Due to carboxylic acid groups on the surface, ND developed hydrogen bonding interaction with PUU. So the acid carbonyl $\mathrm{C}=\mathrm{O}$ (ND) was capable of developing interaction with $\mathrm{N}-\mathrm{H}$ group (PUU), and hydroxyl group (ND) formed hydrogen bonding with urethane $\mathrm{C}=\mathrm{O}$ (Fig. 2). 


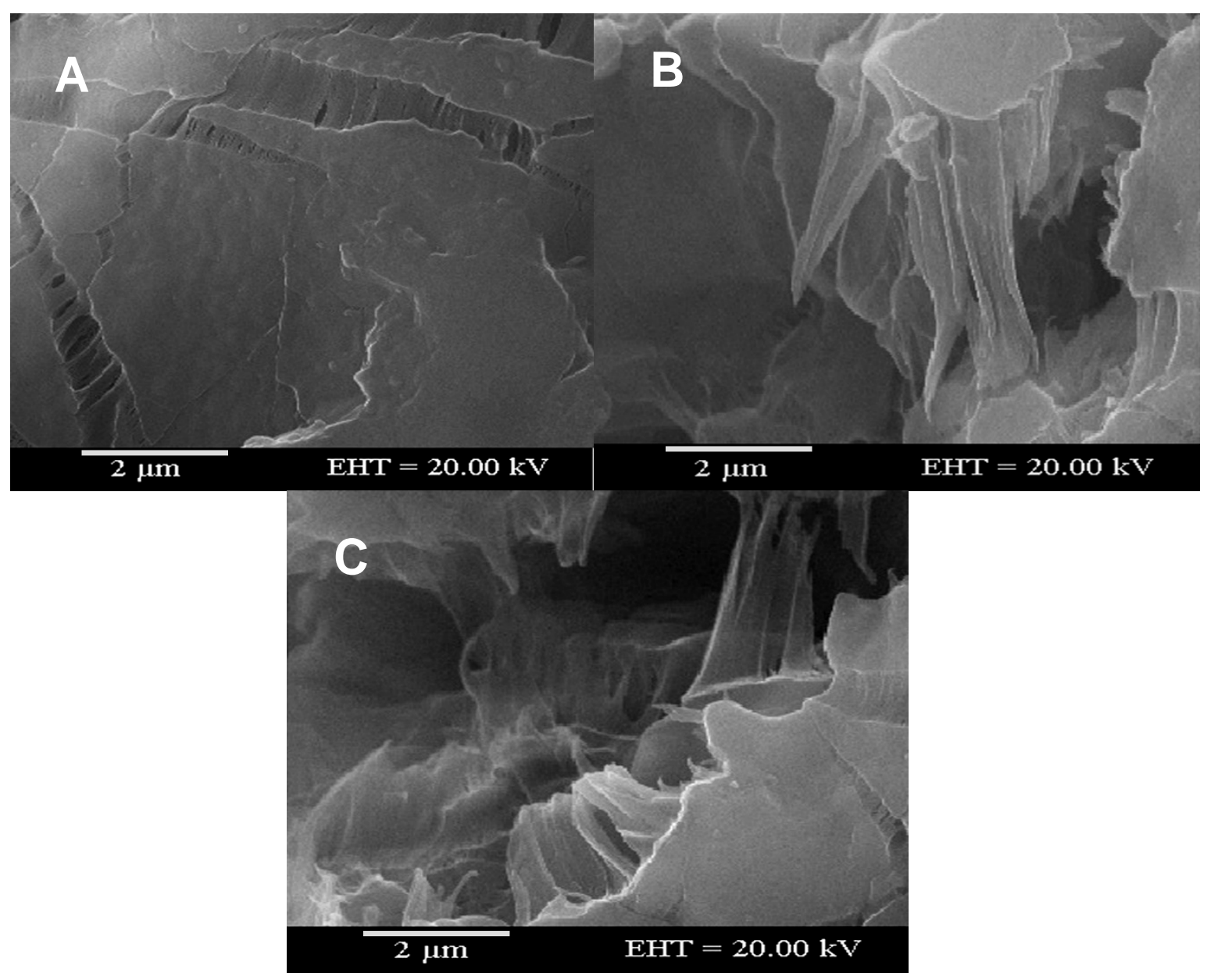

Fig. 5. FESEM images of (A) s-PUU/ND 1; (B) s-PUU/ND 5; and (C) s-PUU/ND 10

\section{Mechanical strength}

Results of the mechanical properties of the composite films are given in Table 1. The tensile strength of s-PUU/ND 1-10 series is shown in Fig. 6. The mechanical properties of the solution processed s-PUU/ND 1-10 composites seem to be dependent on the nanofiller dispersion as well as the compatibility of the two phases. According to literature, higher filler content may cause deterioration in the physical properties of composites due to agglomeration. Therefore the nanodiamond content was varied between 1-10 wt. \%, and not studied beyond that [24]. The properties were also reliant on the nanofiller content. The filler addition in the composites increased the tensile strength progressively. The ultimate tensile strength of s-PUU/ND 1 was increased from 33.9 to $37.8 \mathrm{MPa}$ in s-PUU/ND 10 composite. The tensile modulus was also increased in s-PUU/ND 1-10 composites from 816 to $999 \mathrm{MPa}$. On the other hand the tensile strain was decreased from 7.11 to $6.87 \%$ due to rise in structural rigidity with ND addition. 
Table 1. Mechanical properties of PUU and PUU/ND composite films

\begin{tabular}{lccc}
\hline Composition & $\begin{array}{c}\text { Ultimate Tensile Strength } \\
\text { (MPa) }\end{array}$ & $\begin{array}{c}\text { Elongation at Break (\%) } \\
\text { Young's Modulus } \\
\text { (MPa) }\end{array}$ \\
\hline PUU & 19.3 & 20.4 & 230 \\
s-PUU/ND 1 & 33.9 & 7.11 & 816 \\
s-PUU/ND 3 & 35.1 & 7.09 & 863 \\
s-PUU/ND 5 & 36.1 & 6.97 & 875 \\
s-PUU/ND 10 & 37.8 & 6.87 & 999 \\
m-PUU/ND 1 & 32.8 & 6.99 & 621 \\
m-PUU/ND 3 & 33.8 & 6.95 & 646 \\
m-PUU/ND 5 & 34.7 & 6.75 & 653 \\
m-PUU/ND 10 & 35.7 & 6.69 & 660 \\
\hline
\end{tabular}

The melt processed m-PUU/ND 1-10 composites showed increasing trend in the tensile strength (32.8-35.7 MPa). However the values were lower than the solution caste s-PUU/ND 1-10 composites (Fig. 7). The tensile modulus of the melt series (621-660 MPa) was also lower than that of solution series. Nevertheless the properties were found to increase with in the series with the filler addition. In the melt series addition of $10 \mathrm{wt} . \%$ nanofiller decreased the strain up to $6.69 \%$. The decrease in the elongation at break was due to the formation of brittle polyurethane cross-linked structure with nanodiamond [28, 29].

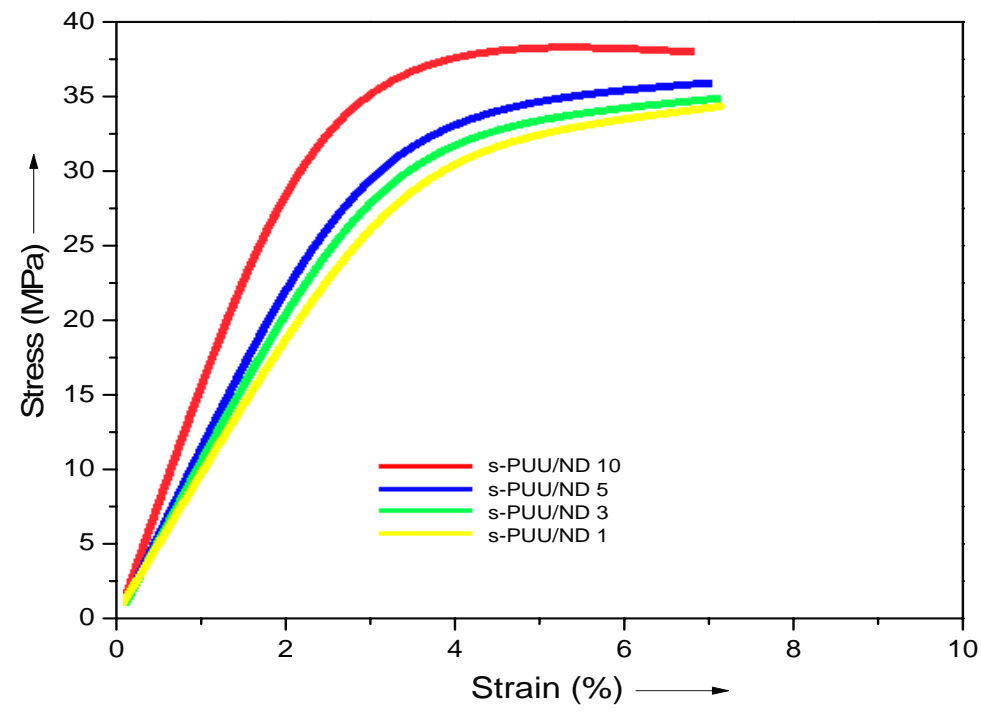

Fig. 6. Plot of ultimate tensile strength of s-PUU/ND composites 


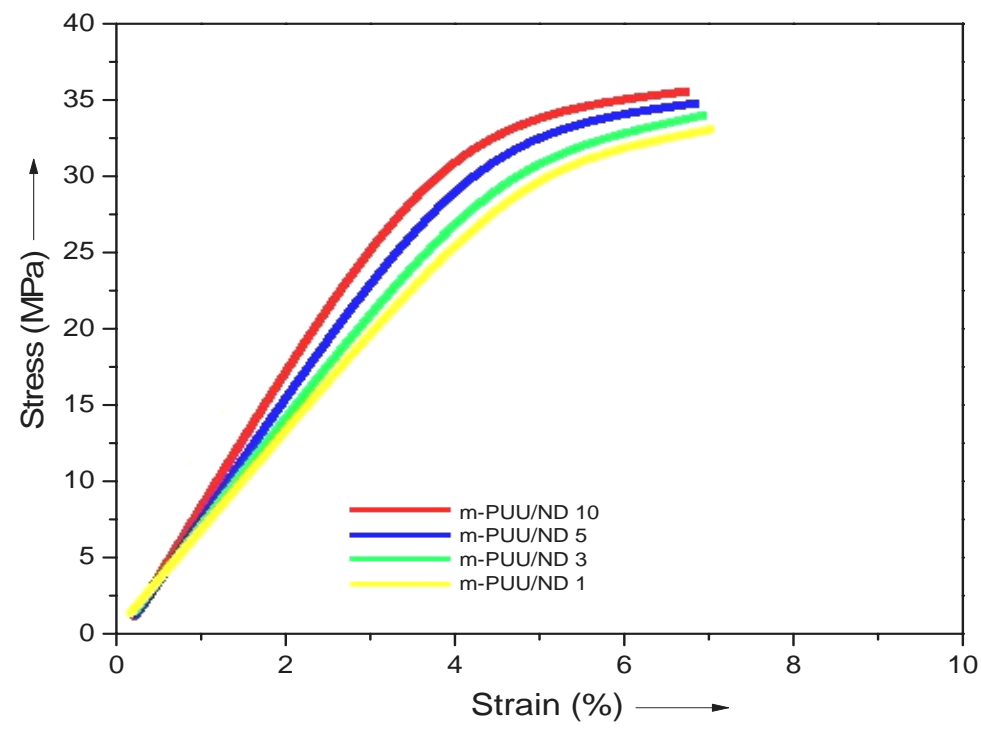

Fig. 7. Plot of ultimate tensile strength of m-PUU/ND composites

\section{Electrical conductivity and voltage effect}

Influence of nanodiamond addition as well as the composite processing technique on the electrical properties of PUU/ND composites was also studied (Table 2).

Table 2. Electrical conductivity and shape recovery of PUU and PUU/ND composites

\begin{tabular}{lcc}
\hline \multicolumn{1}{c}{ Composition } & Electrical conductivity $\left(\mathbf{S c m}^{-\mathbf{1}}\right)$ & Shape Recovery (\%) \\
\hline PUU & $0.88 \times 10^{-1}$ & 85 \\
s-PUU/ND 1 & 0.036 & 92 \\
s-PUU/ND 3 & 0.051 & 92 \\
s-PUU/ND 5 & 0.073 & 94 \\
s-PUU/ND 10 & 0.081 & 95 \\
m-PUU/ND 1 & 0.028 & 89 \\
m-PUU/ND 3 & 0.034 & 90 \\
m-PUU/ND 5 & 0.047 & 91 \\
m-PUU/ND 10 & 0.057 & 91 \\
\hline
\end{tabular}

The room temperature conductivity of s-PUU/ND and m-PUU/ND series is shown in Fig. 8. The conductivity of the composites was increased with the increase in nanodiamond content in both the series. Polymers are normally insulating can be made electrically conductive by adding a conductive filler. The mechanism of electrical conductivity depends on the nature of both the electrically conductive filler and polymer because the mechanism depends on the interaction between the particles of electrically conductive filler and polymer. Increase in filler content cause growth of contacts between PUU and ND and formation of continuous electrically conductive 
structure. The increase in electric conductivity can be explained on the basis of tunneling mechanism. The enhancement in electric conductivity was observed by means of electron tunneling between filler particles. This has been explained by numerous conductive pathways formed via fine contacts of aligned conductive nanodiamonds. The m-PUU/ND 1 composite has electrical conductivity of $0.028 \mathrm{Scm}^{-1}$, while m-PUU/ND 10 attained a value of $0.057 \mathrm{Scm}^{-1}$. The solution formed series showed better results. The $10 \mathrm{wt} . \% \mathrm{ND}$ addition increased the value up to $0.081 \mathrm{Scm}^{-1}$. The sharp increase in the conductivity with $10 \mathrm{wt}$. \% filler addition suggested the formation of polyurethane-nanodiamond conducting network. Fig. 9 shows the temperature change with voltage and time for s-PUU/ND 10 composite. It was observed that the surface temperature increased with time for $10 \mathrm{wt} \% \% \mathrm{ND}$ composite at 25 and $40 \mathrm{~V}$. However, the sample heated at $40 \mathrm{~V}$ demonstrate increased surface temperature with time compared with $25 \mathrm{~V}$ heated samples. Consequently higher electrical conductivity is required to achieve good shape memory polymer actuator.

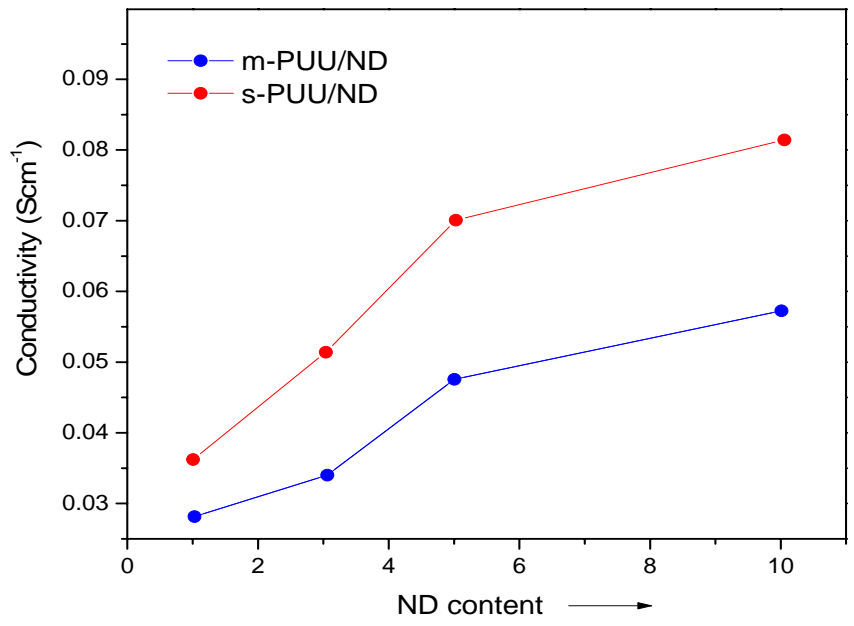

Fig. 8. Conductivity of s-PUU/ND and m-PUU/ND composites

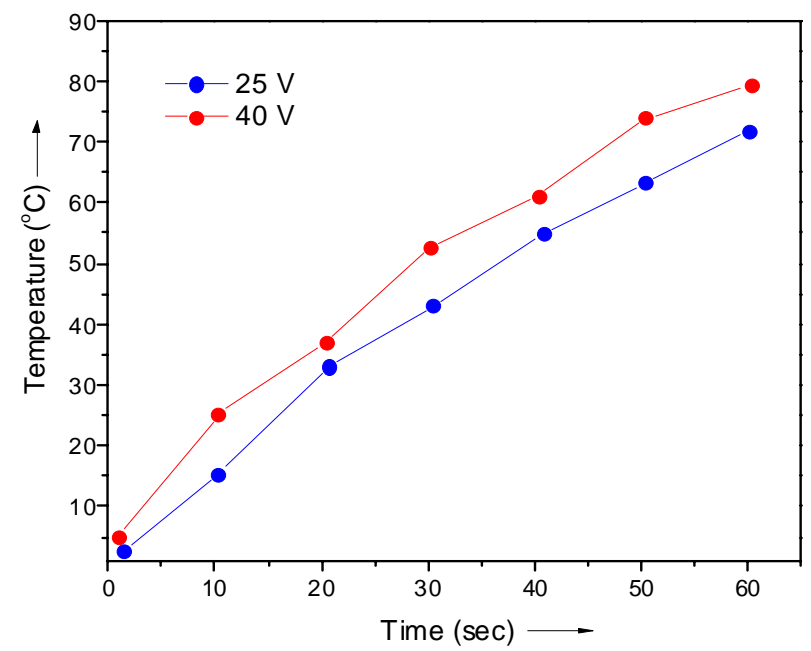

Fig. 9. Temperature change of s-PUU/ND 10 composite surfaces with time at various voltage 


\section{Thermal conductivity}

Fig. 10 shows the thermal conductivity of s-PUU/ND composites. The coefficient of thermal transport was studied by independent Hot-Disk method. Similar to the electrical conductivity, the thermal conductivity of the composites was found to increase with ND loading. Inside the composite materials, thermal conductivity of particles greatly influences the thermal conductivity. In this case, higher thermal conductivity of ND particles is expected to escort higher thermal conductivity of material. The type, content and motion of particles especially Brownian motion may affect the thermal conductivity of materials [30, 31]. The $10 \mathrm{wt} . \% \mathrm{~s}-$ PUU/ND 10 composite has thermal conductivity several orders of magnitude higher than $1 \mathrm{wt} . \%$ filler loaded sample. The thermal conductivity was in the range of $2.0-5.5 \mathrm{~W} / \mathrm{mK}$. On the other hand the m-PUU/ND 1-10 series has lower thermal conductivity of 1.2-1.5 W/mK (Table 3).

Table 3. Thermal conductivity of composites

\begin{tabular}{lc}
\hline \multicolumn{1}{c}{ Samples } & $\begin{array}{c}\text { Thermal conductivity } \\
\text { (W/mK) }\end{array}$ \\
\hline PUU & 1.1 \\
s-PUU/ND 1 & 2.1 \\
s-PUU/ND 3 & 3.6 \\
s-PUU/ND 5 & 4.5 \\
s-PUU/ND 10 & 5.5 \\
m-PUU/ND 1 & 1.2 \\
m-PUU/ND 3 & 1.3 \\
m-PUU/ND 5 & 1.4 \\
m-PUU/ND 10 & 1.5 \\
\hline
\end{tabular}

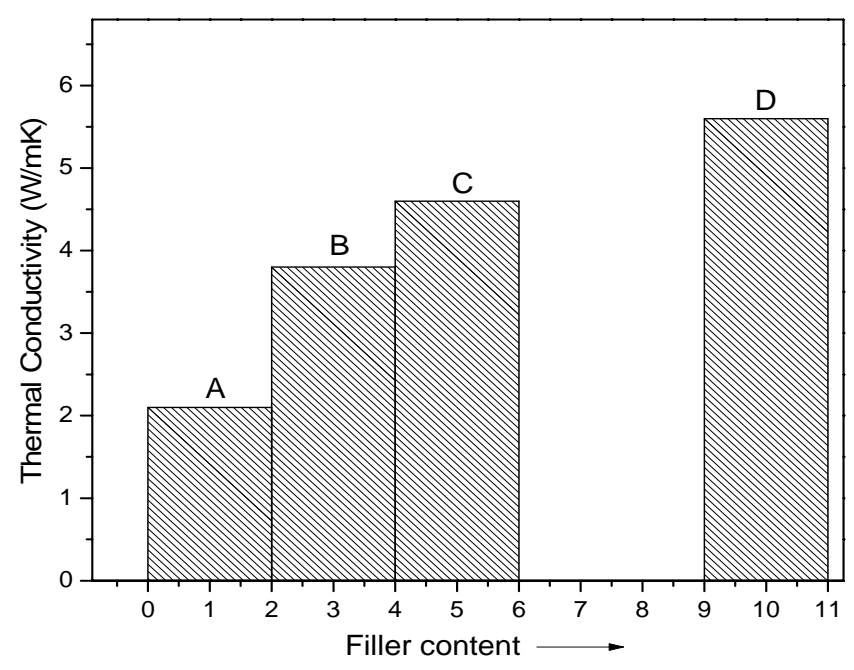

Fig. 10. Thermal conductivity of (A) s-PUU/ND 1; (B) s-PUU/ND 3; (C) s-PUU/ND 5; and (D) s-PUU/ND 10 


\section{Electroactive shape memory effect}

Electric field-triggered shape recovery of the s-PUU/ND and m-PUU/ND series is shown in Table 2. Prior to the applied voltage the sample was a rectangular strip. It was deformed into a round shape using liquid nitrogen. Its shape was changed spontaneously when the constant voltage $(40 \mathrm{~V})$ was applied. The original shape of the sample was almost $95 \%$ recovered in $40 \mathrm{~s}$ (s-PUU/ND 10). The s-PUU/ND 10 composites showed better shape recovery of $92-95 \%$ with in $40 \mathrm{~s}$. Moreover the good electrical conductivity at higher filler loading and optimal mechanical properties was important to demonstrate the electroactive shape memory behavior in composites. As melt series comparatively possess lower electrical conductivity, the shape recovery was also lower (89-91\%).

\section{CONCLUSION}

Shape memory composites of poly(urethane-urea)/nanodiamond were fabricated using two techniques i.e. solution casting and melt technique. The poly(urethane-urea) was prepared having branched and crosslinked structure because of the employment of polycaprolactone triol soft segment. Use of the acid functional nanodiamond filler was responsible for the formation of network structure via hydrogen bonding with PUU. The network intern was responsible for high ultimate tensile strength and electrical conductivity of the composites. The solution processed composites revealed better results due to better nanofiller dispersion and polyurethane/nanodiamond interaction. Young's Modulus and ultimate tensile were found to increased relative to pure PUU when the filler content was raised to $10 \mathrm{wt} . \%$. The electrical conductivity of s-PUU/ND 10 composites of $0.081 \mathrm{Scm}^{-1}$ was enough to demonstrate electroactive shape memory with bending mode. The original shape of the sample was almost 95 $\%$ recovered in $40 \mathrm{~s}$ with an electric field of $40 \mathrm{~V}$.

\section{REFERENCES}

1. Suna L., Huang W. M., Ding Z., Zhao Y., Wang C. C., Purnawali H., Tang C.: Stimulus-responsive shape memory materials: A review, Mater. Des. 33 (2012) 577-640.

2. Hu J., Zhu Y., Huang H., Lu J.: Recent advances in shape-memory polymers: Structure, mechanism, functionality, modeling and applications, Prog. Polym. Sci. 37 (2012) 1720-1763.

3. Kumar U. N., Kratz K., Wagermaier W., Behla M., Lendlein A.: Non-contact actuation of triple-shape effect in multiphase polymer network nanocomposites in alternating magnetic field, J. Mater. Chem. 20 (2010) 3404-3415.

4. Leng J., Lan X., Liu Y., Du S.: Shape-memory polymers and their composites: Stimulus methods and applications, Prog. Mater. Sci. 56 (2011) 1077-1135. 
5. Leng J. S., Huang W. M., Lan X., Liu Y. J., Du S. Y.: Significantly reducing electrical resistivity by forming conductive Ni chains in a polyurethane shape-memory polymer/carbon-black composite, Appl. Phys. Lett. 92 (2008) 204101.

6. Zhao Q., Behl M., Lendlein A.: Shape-memory polymers with multiple transitions: complex actively moving polymers, Soft Matter 9 (2013) 1744-1755.

7. Liu Y., Du H., Liu L., Leng J.: Shape memory polymers and their composites in aerospace applications: a review, Smart Mater. Struct. 23 (2014) 023001.

8. Maitland D. J., Metzger M. F., Schumann D., Lee A., Wilson T.S.: Photothermal properties of shape memory polymers micro-actuators for treating stroke, Laser Surg. Med. 30 (2002) 1-11.

9. Ratna D., Karger-Kocsis J.: Recent advances in shape memory polymers and composites: a review, J. Mater. Sci. 43 (2008) 254-269.

10. Gu X., Mather P. T.: Entanglement-based shape memory polyurethanes: synthesis and characterization, Polymer 53 (2012) 5924-5934.

11. Behl M.: Lendlein A.: Shape-memory polymers, Mater. Today 10 (2007) 20-28.

12. Yang B., Huang W. M., Li C., Li L.: Effect of moisture on the thermomechanical properties of a polyurethane shape memory polymer, Polymer 47 (2006) 1348-1356.

13. Yeh F., Hsiao B. S., Sauer B. B., Michel S., Siesler H. W.: In-Situ Studies of Structure Development during Deformation of a Segmented Poly(urethane-urea) Elastomer, Macromolecules 36 (2003) 19401954.

14. Wu C., Huang X., Wang G., Wu X., Yang K., Li S., Jiang P.: Hyperbranched-polymer functionalization of graphene sheets for enhanced mechanical and dielectric properties of polyurethane composites, $\mathrm{J}$. Mater. Chem. 22 (2012) 7010-7019.

15. Ahmed N., Kausar A., Muhammad B.: Shape Memory Properties of Electrically Conductive MultiWalled Carbon Nanotube Filled Polyurethane/Modified Polystyrene Blends, J. Plast. Film Sheet. (2015) DOI: $10.1177 / 8756087915595454$.

16. Gall K., Kreiner P., Turner D., Hulse M.: Shape-memory polymers for microelectromechanical systems, J. MEMS 13 (2004) 472-483.

17. Ahmed N., Kausar A., Muhammad B.: Advances in Shape Memory Polyurethanes and Composites: A Review, Polym-Plast Technol. and Eng. (2015) DOI:10.1080/03602559.2015.1021490.

18. El Hasnaoui M., Triki A., Graça M. P. F., Achour M. E., Costa L. C., Arous M.: Electrical conductivity studies on carbon black loaded ethylene butylacrylate polymer composites, J. Non-Cryst. Sol. 358 (2012) 2810-2815.

19. El Hasnaoui M., Triki A., Achour M. E., Arous M.: Modelling of dielectric relaxation processes of epoxy-resin filled with carbon black particles, Phys. B Condens. Matt. 15 (2014) 62-66.

20. Elhad Kassim S. A., Achour M. E., Costa L. C., Lahjomri F.: Modelling the DC electrical conductivity of polymer/carbon black composites, J. Electrostat. 72 (2014) 187-191.

21. Li F., Qi L., Yang J., Xu M., Luo X., Ma D.: Polyurethane/Conducting Carbon Black Composites: Structure, Electric Conductivity, Strain Recovery Behavior, and Their Relationships, J. Appl. Polym. Sci. 75 (2000) 68-77.

22. Cho J. W., Kim J. W., Jung Y. C., Goo N.S.l: Electroactive shape-memory polyurethane composites incorporating carbon nanotubes, Macromol. Rapid Commun. 26 (2005) 412-414. 
23. Sattar R., Kausar A., Siddiq, M.: Advances in thermoplastic polyurethane composites reinforced with carbon nanotubes and carbon nanofibers: A review, J. Plast. Film Sheet. 31 (2015) 186-224.

24. Ashraf R., Kausar A., Siddiq M.: High performance multi-layered polymer/nanodiamond composites: synthesis and properties, Iran. Polym. J. 23 (2014) 531-545.

25. Kausar A., Wajid-Ullah, Muhammad B., Siddiq M.: Novel Mechanically Stable, Heat Resistant and Non-flammable Functionalized Polystyrene/Expanded Graphite Nanocomposites, Adv. Mater. Sci. (2014) DOI: 10.2478/adms-2014-0022.

26. Meador M. N. B., Hardy-Green D., Auping J. V., Gaier J. R., Ferrara L. A., Papadopoulos D. S., Smith J. W., Keller D. J.: Optimization of electrically conductive films: Poly(3-methylthiophene) or polypyrrole in Kapton. J. Appl. Polym. Sci. 63 (1997) 821-834.

27. Jung Y. C., Sahoo N. G., Cho J. W.: Polymeric nanocomposites of polyurethane block copolymers and functionalized multi-walled carbon nanotubes as crosslinkers, Macromol. Rapid Commun. 27 (2006)

126-131.

28. Ghosh P., Chakraborty A., Kar S. B., Chowdhury R.: Conducting blends of poly(o-toluidine) and poly(ester)urethane. Synth. Met. 144 (2004) 241-247.

29. Sahoo N. G., Jung Y. C., Yoo H. J., Cho J. W.: Influence of carbon nanotubes and polypyrrole on the thermal, mechanical and electroactive shape-memory properties of polyurethane nanocomposites. Compos. Sci. Technol. 67 (2007) 1920-1929.

30. Xuan, Y., Li, Q., Hu, W.: Aggregation structure and thermal conductivity of nanofluids. AIChE Journal 49 (2003) 1038-1043.

31. Lee, D.: Thermophysical properties of interfacial layer in nanofluids. Langmuir. 23 (2007) 6011-6018. 